\title{
The Change of Total Anthocyanins in Blueberries and Their Antioxidant Effect After Drying and Freezing
}

\author{
Virachnee Lohachoompol, George Srzednicki,* and John Craske \\ Food Science and Technology, School of Chemical Engineering and Industrial Chemistry, \\ The University of New South Wales, Sydney, NSW 2052, Australia
}

Received 26 April 2004; revised 11 June 2004; accepted 29 June 2004

\begin{abstract}
This study examined the effects of freezing, storage, and cabinet drying on the anthocyanin content and antioxidant activity of blueberries (Vaccinium corymbosum $\mathrm{L}$ ). Fresh samples were stored for two weeks at $5{ }^{\circ} \mathrm{C}$ while frozen samples were kept for up to three months at $-20^{\circ} \mathrm{C}$. There were two drying treatments, one including osmotic pretreatment followed by cabinet drying and the other involving only cabinet drying. Total anthocyanins found in fresh blueberries were $7.2 \pm 0.5 \mathrm{mg} / \mathrm{g}$ dry matter, expressed as cyanidin 3 -rutinoside equivalents. In comparison with fresh samples, total anthocyanins in untreated and pretreated dried blueberries were significantly reduced to $4.3 \pm 0.1 \mathrm{mg} / \mathrm{g}$ solid content, $41 \%$ loss, and $3.7 \pm 0.2 \mathrm{mg} / \mathrm{g}$ solid content, $49 \%$ loss, respectively. Osmotic treatment followed by a thermal treatment had a greater effect on anthocyanin loss than the thermal treatment alone. In contrast, the frozen samples did not show any significant decrease in anthocyanin level during three months of storage. Measurement of the antioxidant activity of anthocyanin extracts from blueberries showed there was no significant difference between fresh, dried, and frozen blueberries.
\end{abstract}

\section{INTRODUCTION}

Anthocyanins, natural pigments which are responsible for the blue, purple, violet, and red colours of fruit, are one of the major flavonoid classes [1]. The major sources of anthocyanins in edible plants are families Vitaceae (grape) and Rosaceae (cherry, plum, raspberry, strawberry, blackberry, apple, peach, etc.). Other plant families which contain anthocyanin pigments are Solanaceae (tamarillo and eggplant), Saxifragaceae (red and black currants), Cruciferae (red cabbage), and Ericaceae (blueberry and cranberry) [2]. Blueberries contain the following anthocyanins: malvidin 3-galactoside, delphinidin 3-galactoside, delphinidin 3-arabinoside, petunidin 3-galactoside, petunidin 3-arabinoside, malvidin 3-arabino-side, cyanidin 3glucoside, cyanidin 3-galactoside, cyanidin 3-arabinoside, delphinidin 3-glucoside, malvidin 3-glucoside, peonidin 3-glucoside, peonidin 3-galactoside, peonidin 3arabinoside, and peonidin 3-glucoside [3].

Flavonoids such as flavones, isoflavones, flavonones, anthocyanins, and catechins have strong antioxidant capacity [4]. These compounds can be found in cereal grains, tubers, tea, coffee, fruits, and vegetables. The berries, such as blueberries, are significant sources of anthocyanins. Methanol extracts from Vaccinium angustifolium L and cultivar Fundy possess higher antioxidant activity than sweet cherry, potato (purple), wheat germ, and ginseng root [5].
The consumption of wild blueberries, a food source with high in vitro antioxidant properties, is associated with a diet-induced increase in ex vivo serum antioxidant status [6]. Anthocyanins in grape juice reduced in vitro oxidation of human low-density lipoprotein (LDL) [7]. Potential bioavailability, in humans, of several anthocyanins from red wine was tested. Within 12 hours after $300 \mathrm{~mL}$ of wine consumption, $1.5 \%-5.1 \%$ of the ingested anthocyanins were found in urine. Two compounds among the wine anthocyanins were unchanged while the others, which were considered by the authors, seemed to have undergone molecular modifications [8]. Frozen, liquid-extracted, and freeze-dried powders, made from wild blueberries, were used in a study of bioactive properties, which included antioxidant activity, cardioprotective capacity, and cancer chemoprevention activity. Many fractions of the extracts showed antioxidant activities, especially those rich in anthocyanins and proanthocyanidins [9]. Anthocyanins have been found to significantly suppress the growth of cultured tumour cells and have been shown to have greater inhibitory effect than other flavonoids $[10,11]$.

Blueberries are commercialised in different ways, mainly as fresh or frozen products. Freezing and drying are two possible methods to preserve blueberries but the severity of both processes might destroy anthocyanins or their antioxidant effects. Blueberries are known for their bioactive properties such as antioxidant activity, cardiovascular protection, antidiabetic properties, vision 
improvement properties, and inhibition of carcinogenesis and mutagenesis [12]. Thus, the aim of this study was to determine and to compare total anthocyanins and their antioxidant effects in frozen or dried blueberries and to compare them with the values found in fresh berries.

\section{MATERIALS AND METHODS}

\section{Samples}

Fresh blueberries (Vaccinium corymbosum L) were supplied by Blueberry Farms of Australia P/L, Corindi Beach, New South Wales, Australia.

\section{Treatments}

Fresh blueberries were kept at $5^{\circ} \mathrm{C}$ for up to two weeks before extraction (FR2). Several batches of blueberries were frozen and kept at $-20^{\circ} \mathrm{C}$ up to 3 months. The samples were taken and examined at 1-month (FZ1M) and 3month (FZ3M) storage. There were 2 replicates for each sampling point.

Two batches of blueberries weighing $1 \mathrm{~kg}$ each were dried. The first batch, PT, had been treated with $60 \%$ w/w sugar and $1 \% \mathrm{w} / \mathrm{w} \mathrm{NaCl}$ solution for 4 hours and slowly dried in a cabinet dryer at $90^{\circ} \mathrm{C}$ for 90 minutes, followed by $70^{\circ} \mathrm{C}$ for 120 minutes, and finally $50^{\circ} \mathrm{C}$ for $120 \mathrm{~min}$ utes. The second batch, UN, was dried directly without any pretreatment using the same temperature profile.

Dry matter was determined by drying $5-10 \mathrm{~g}$ blueberry sample in a vacuum oven at $70^{\circ} \mathrm{C}, 85 \mathrm{kPa}$ for 72 hours. The dried blueberries were weighed again and the dried matter that remained was determined. Total anthocyanins and antioxidant effect from dried samples (UN and PT) were compared with those of frozen and fresh samples.

\section{Anthocyanin extraction}

Samples weighing $20 \mathrm{~g}$ of fresh, frozen, and proportionally reduced amounts (based on moisture loss during drying) of dried blueberries were blended in a food processor for 1 minute with $150 \mathrm{~mL}$ of a mixture of methanol, acetic acid, and distilled water (M:A:W) at a ratio of 25:1:24. Frozen blueberries were thawed in a refrigerator $\left(\right.$ at about $\left.5^{\circ} \mathrm{C}\right)$ overnight prior to the extraction. Half of the well-blended solution was centrifuged at $21900 \mathrm{~g}$ $(12000 \mathrm{rpm})$ for 20 minutes at $20^{\circ} \mathrm{C}$. The remaining residue from centrifugation after the supernatant was removed was mixed thoroughly with $75 \mathrm{~mL}$ M:A:W, centrifuged, and the supernatant was separated. Each sample was extracted 3 times. The clear liquid from the 3 extractions was evaporated under vacuum at $35^{\circ} \mathrm{C}$. The residue from vacuum evaporation was redissolved with $5 \mathrm{~mL}$ of $3 \%(\mathrm{w} / \mathrm{v})$ formic acid in water. This aqueous solution was adsorbed on a C18 Sep-Pak cartridge. The cartridge was washed with $5 \mathrm{~mL}$ of $3 \%(\mathrm{w} / \mathrm{v})$ formic acid in water and eluted with $3.5 \mathrm{~mL}$ of $3 \%(\mathrm{w} / \mathrm{v})$ formic acid in methanol. The anthocyanins eluted from the cartridge were evaporated under vacuum at $35^{\circ} \mathrm{C}$ until dryness [13].

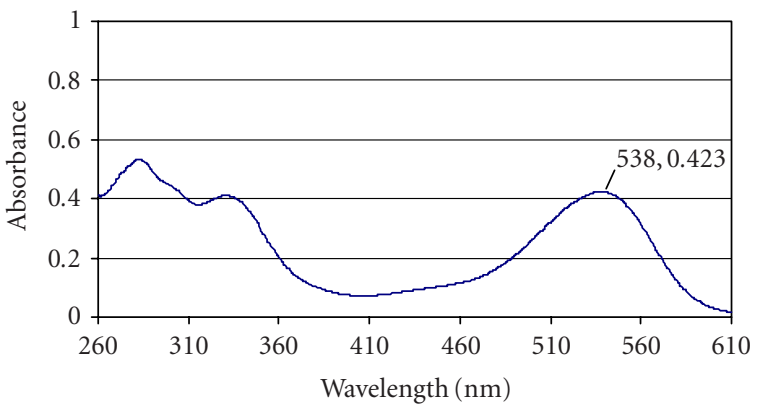

FIgURE 1. Scan spectrum of blueberry extracts in $\mathrm{MeOH}: \mathrm{HCl}$.

\section{Determination of total anthocyanins}

The residue was diluted to the volume of $25 \mathrm{~mL}$ by mixing with the mixture of methanol and $0.1 \mathrm{M} \mathrm{HCl}$ at a ratio of $85: 15(\mathrm{MeOH}: \mathrm{HCl})$. The anthocyanin solution was diluted to the appropriate concentration for measurement of absorbance in the Cary 100 scanning UVVis spectrophotometer using $1 \mathrm{~cm}$ path length quartz cells at $538 \mathrm{~nm}$. Total anthocyanins were expressed as cyanidin 3-rutinoside equivalents [14]. The molar absorptivity of cyanidin 3-rutinoside was equal to 31085 at $530 \mathrm{~nm}$ in $\mathrm{MeOH}: \mathrm{HCl}$. This molar absorptivity has been determined experimentally.

\section{Antioxidant effects}

The antioxidant activity of the anthocyanin extracts was measured using a free radical method of BrandWilliams et al [15]. The free radical used in this study was 2, 2-diphenyl-1-picrylhydrazyl (DPPH). The UV$1601 \mathrm{UV}-$ Vis spectrophotometer was used to determine the concentration of DPPH. $3.9 \mathrm{~mL}$ of $6 \times 10^{-5} \mathrm{~mol} / \mathrm{L}$ DPPH in methanol (spectrophotometric grade) were put into the disposable cuvette with $0.1 \mathrm{~mL}$ of anthocyanin extract. The decrease of absorbance was measured at 0 minute, 1 minute, and every 5 minutes at $515 \mathrm{~nm}$ for 2 hours or until the absorbance became steady. The remaining DPPH concentration $\left(\mathrm{C}_{\mathrm{DPPH}}\right)$ was calculated using the following equation [15]:

$$
\mathrm{C}_{\mathrm{DPPH}}=\left(\mathrm{Abs}_{515}+2.58 \times 10^{-3}\right) \times 12509^{-1} .
$$

\section{Statistical analysis}

The data were analysed by analysis of variance (ANOVA) method and Duncan, multiple-range test at 5\% level of significance using SPSS.

\section{RESULTS AND DISCUSSION}

\section{Total anthocyanins}

A spectrum of the blueberry extract is presented in Figure 1. In the anthocyanin extracts, the peak in the visible region was recorded at $538 \mathrm{~nm}$ while the peaks in the UV range were at 280 and $320 \mathrm{~nm}$. The presence of these 
TABLe 1. Anthocyanin content in evaluated samples.

\begin{tabular}{lc}
\hline Blueberry samples & $\begin{array}{c}\text { Total anthocyanins } \\
\mathrm{mg} / \mathrm{g} \text { dry matter }\end{array}$ \\
\hline $\begin{array}{l}\text { Fresh blueberries (FR0) } \\
\text { Fresh blueberries 2-week }\end{array}$ & $7.2 \pm 0.5^{\mathrm{a} * *}$ \\
storage at $5^{\circ} \mathrm{C}(\mathrm{FR} 2)$ & $5.7 \pm 0.5^{\mathrm{ab}}$ \\
Untreated dried (UN) & $4.3 \pm 0.1^{\mathrm{bc}}$ \\
Pretreated dried (PT) & $3.7 \pm 0.2^{\mathrm{c}}$ \\
Stored frozen for 1 month (FZ1M) & $8.1 \pm 0.1^{\mathrm{a}}$ \\
Stored frozen for 3 months (FZ3M) & $7.9 \pm 1.3^{\mathrm{a}}$ \\
\hline
\end{tabular}

* Total anthocyanin as cyanidin 3-rutinoside equivalent.

** Mean \pm standard deviation of duplicate samples. The means that have the same superscript are not significantly different $(P<.05)$.

peaks reflects the fact that blueberries contain a mix of anthocyanins and other phenolic compounds.

One sample of fresh blueberries, (FR0), was extracted immediately after having been received from the grower while another sample, (FR2), was kept at $5^{\circ} \mathrm{C}$ for 2 weeks before extraction. Total anthocyanins in FR2 were slightly lower than those in FR0; namely, 5.7 and $7.2 \mathrm{mg} / \mathrm{g}$ dry matter, respectively (Table 1 ). The blueberries that had been stored for two weeks at $5^{\circ} \mathrm{C}$ were softer. In a study by Sapers and Phillips [16], the leakage of anthocyanins was proportional to the percentage of soft berries in the whole sample. In comparison with other fruits such as plums, the concentration of anthocyanins found in 2-week refrigerated blueberries was higher $(5.7 \pm 0.5 \mathrm{mg} / \mathrm{g}$ dry matter $)$ than that found in fresh plums, which was in the range of $2.6-5.2 \mathrm{mg} / \mathrm{g}$ dry matter [14].

The total anthocyanin content in both dried samples UN and PT was less than that in fresh berries (Table 1). The percentage of loss of anthocyanins in UN was $41 \%$ while it increased to $49 \%$ in PT. Slightly higher reduction in anthocyanin content was observed in PT than in UN. However, the difference was not statistically significant. This difference was caused by the 4 -hour pretreating step that leached out some anthocyanins. Anthocyanin leakage might happen due to dewaxing, which was caused by stirring and soaking during the osmotic pretreatment. This observation is comparable to the study by Sapers and Phillips [16] who found that dewaxing weakened the berry cuticle and allowed the skin to rupture. This permitted some leakage from the exposed edges or undersurface of the torn skin to the osmotic solution that caused anthocyanin loss before the drying step. Also, the thermal processing destroyed some anthocyanins. A study about the evolution of anthocyanins in raspberries during jam making, in which heat was used, showed that $17 \%-40 \%$ of anthocyanins were lost [17].

As for the appearance, the PT samples presented a more shiny aspect than the UN samples. Furthermore, the moisture content after drying of PT (33.6\% wet basis) was lower than that of UN ( $36.9 \%$ wet basis).

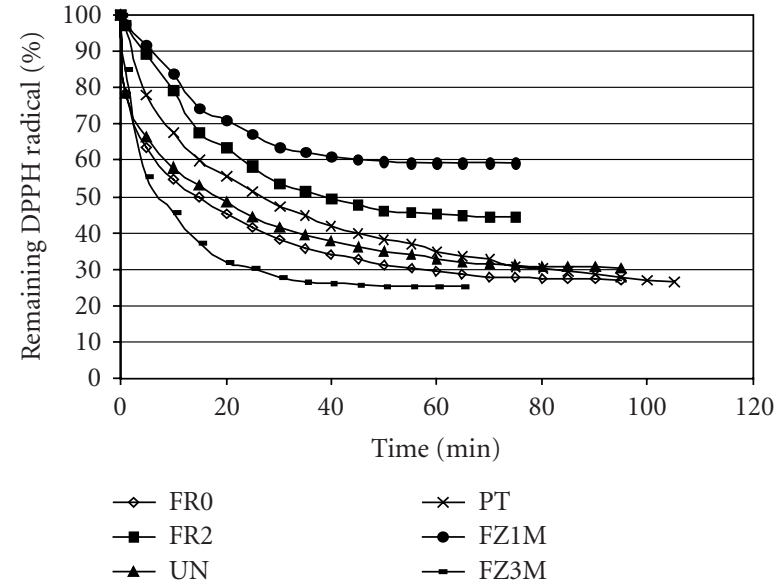

Figure 2. Kinetic behaviour of reducing DPPH radical of anthocyanins found in blueberry extract after the following treatments: FR0 : fresh blueberries; FR2: fresh blueberries kept at $5^{\circ} \mathrm{C}$ for two weeks; UN : untreated blueberries dried in a cabinet dryer; PT : osmotically pretreated blueberries dried in a cabinet dryer; FZ1M : frozen blueberries kept at $-20^{\circ} \mathrm{C}$ for 1 month; FZ3M : frozen blueberries kept at $-20^{\circ} \mathrm{C}$ for 3 months.

Anthocyanin contents of frozen samples were found stable over 3 months of storage (Table 1). The fruits, which were stored frozen for 1 month (FZ1M) and 3 months (FZ3M), showed no significant difference from FR0.

\section{Antioxidant effect}

The results of the kinetic behaviour of blueberry extracts are shown in Figure 2. After adding the blueberry extract to the DPPH solution, the absorbance was increased due to the colour of the extracts. The slope of the equations may be a useful parameter to define the antioxidant capacity. The steeper the slope, the lower the amount of antioxidant that is necessary to decrease by $50 \%$ the initial DPPH concentration [18]. The steepest slope was that of FZ3M (Table 2). This means a lower amount of the extract was necessary to decrease the initial DPPH concentration. FZ1M showed the lowest antioxidant activity (though not the lowest anthocyanin content), while there was no significant difference in antioxidant effect between FZ3M and FR0.

Antioxidant activity can also be assessed by the oxygen radical absorbance capacity (ORAC). The ORAC method estimates the antioxidant capacity of a sample by taking the oxidation reaction to completion whereas DPPH estimates the stable free radical and thus is more appropriate to characterise the antioxidant activity in a food sample. In a study of the commercial frozen lowbush blueberries, which contained lower levels (60\%-80\%) of "blue" than the other samples, it was found that the antioxidant activity (ORAC) was comparable to that of the fresh fruits [19]. This result supported an earlier study on variation in ORAC based on variety, maturity, and source, done by Prior et al [20]. 
TABLE 2. Average slope values of blueberry extracts.

\begin{tabular}{lc}
\hline Blueberry extracts & $\begin{array}{c}\text { Slope* }^{*} \\
(\% \mathrm{DPPH} / \mathrm{min})\end{array}$ \\
\hline FR0 & $-0.0110^{\mathrm{ab}}$ \\
FR2 & $-0.01035^{\mathrm{ab}}$ \\
UN & $-0.0103^{\mathrm{ab}}$ \\
PT & $-0.0116^{\mathrm{ab}}$ \\
FZ1M & $-0.0076^{\mathrm{a}}$ \\
FZ3M & $-0.0145^{\mathrm{b}}$ \\
\hline
\end{tabular}

*Slopes that have the same superscript are not significantly different $(P<.05)$.

As for the dried products, UN and PT, samples showed no significant difference in antioxidant activity from the fresh berries even though the anthocyanin contents shown in Table 1 were lower than those in the fresh samples. According to similar studies [20,21], the correlation coefficient between ORAC and the total phenolics was higher than the correlation coefficient between ORAC and total anthocyanins. In a study of total phenolics in blueberries [22], chlorogenic acid, a major colourless phenolic of blueberries, was found at the level of $60-100 \mathrm{mg} / 100 \mathrm{~g}$ of fresh berries and significantly contributed to ORAC [23]. The anthocyanins breakdown products from drying process might act as antioxidants without being affected by the thermal process.

\section{CONCLUSIONS}

The amount of total anthocyanins in the frozen samples, expressed as cyanidin 3-rutinoside equivalents, was not significantly different from that in the fresh samples. In contrast, the concentration of anthocyanins in dried blueberries (UN and PT) was significantly reduced in comparison with that in fresh blueberries while antioxidant activity of the extracts did not differ from that of the fresh fruit. Fruit drying resulted in reduction of the total anthocyanin level by $41 \%$. When drying was preceded with osmotic dehydration, $49 \%$ of anthocyanins were lost. There was no significant difference in antioxidant activity between the anthocyanin extracts of the frozen or dried samples and the fresh fruit. Antioxidant activity in blueberries is an appealing characteristic to consumers. Any processing method that maintains the level of compounds known for their health benefits will be of interest to the food industries.

\section{ACKNOWLEDGMENT}

The authors would like to thank Blueberry Farms of Australia, Corindi Beach, New South Wales, Australia, for providing blueberries used in this study.

\section{REFERENCES}

[1] Gross J. Pigments in Fruits. London: Academic Press; 1987.

[2] Jackman RL, Smith JL. Anthocyanins and betalains. In: Hendry GAF, Houghton JD, eds. Natural Food Colorants. 2nd ed. London: Blackie Academic \& Professional; 1996:244-280.

[3] Mazza G, Miniati E. Anthocyanins in Fruits, Vegetables and Grains. 1st ed. Florida, Fla:CRC Press; 1993.

[4] Wang H, Cao G, Prior RL. Oxygen radical absorbing capacity of anthocyanins. J Agric Food Chem. 1997;45(2):304-309.

[5] Velioglu YS, Mazza G, Gao L, Oomah BD. Antioxidant activity and total phenolics in selected fruits, vegetables, and grain products. J Agric Food Chem. 1998;46:4113-4117.

[6] Frankel EN, Bonasek CA, Meyer AS, Silliman K, Kirk LL. Commercial grape juices inhibit the in vitro oxidation of human low-density lipoproteins. J Agric Food Chem. 1998;46:834-838.

[7] Kay CD, Holub BJ. The effect of wild blueberry ( Vaccinium angustifolium) consumption on postprandial serum antioxidant status in human subjects. $\mathrm{Br} J$ Nutr. 2002;88(4):389-398.

[8] Lapidot T, Harel S. Bioavailability of red wine anthocyanins as detected in human urine. J Agric Food Chem. 1998;46(10):4297-4302.

[9] Smith MAL, Marley KA, Seigler D, Singletary KW, Meline B. Bioactive properties of wild blueberry fruits. Journal of Food Science. 2000;65(2):352356.

[10] Mazza G. Health aspects of natural colors. In: Lauro GJ, Francis FJ, eds. Natural Food Colorants. New York, NY: Marcel Dekker; 2000:289-314.

[11] Kamei H, Kojima T, Hasegawa M, et al. Suppression of tumor cell growth by anthocyanins in vitro. Cancer Invest. 1995;13(6):590-594.

[12] Camire, ME. Bilberries and blueberries as functional foods and nutraceuticals. In: Mazza G, Oomah BD, eds. Functional Foods: Herbs, Botanicals and Teas. Lancaster: Technomic Publishing; 2000:289-319.

[13] García-Viguera C, Zafrilla P, Tomás-Barberán FA. Determination of authenticity of fruit jams by HPLC analysis of anthocyanins. Journal of the Science of Food and Agriculture. 1997;73(2):207-213.

[14] Cinquanta L, Di Matteo M, Esti M. Physical pretreatment of plums (Prunus domestica). Part 2. Effect on the quality characteristics of different prune cultivars. Food Chemistry. 2002;79(2):233-238.

[15] Brand-Williams W, Cuvelier ME, Berset C. Use of free radical method to evaluate antioxidant activity. Lebensmittel Wissenschaft und Technologie. 1995;28:25-30.

[16] Sapers GM, Phillips JG. Leakage of anthocyanins from skin of raw and cooked highbush blueberries (Vaccinium corymbosum L.). Journal of Food Science. 1985;50(2):437-439, 443. 
[17] García-Viguera C, Zafrilla P, Artés F, Romero F, Abellán P, Tomás-Barberán FA. Colour and anthocyanin stability of red raspberry jam. Journal of the Science of Food and Agriculture. 1998;78:565-573.

[18] Sánchez-Moreno C, Larrauri JA, Saura-Calixto F. A procedure to measure the antiradical efficiency of polyphenols. Journal of the Science of Food and Agriculture. 1998;76:270-276.

[19] Kalt W, McDonald JE, Donner H. Anthocyanins, phenolics, and antioxidant capacity of processed lowbush blueberry products. Journal of Food Science. 2000;65(3):390-393.

[20] Prior RL, Cao G, Martin A, et al. Antioxidant capacity as influenced by total phenolic and anthocyanin content, maturity, and variety of Vaccinium species. $J$ Agric Food Chem. 1998;46(7):2686-2693.

[21] Moyer RA, Hummer KE, Finn CE, Frei B, Wrolstad RE. Anthocyanins, phenolics, and antioxidant capacity in diverse small fruits: vaccinium, rubus, and ribes. J Agric Food Chem. 2002;50(3):519-525.

[22] Gao L, Mazza G. Quantitation and distribution of simple and acylated anthocyanins and other phenolics in blueberries. Journal of Food Science. 1994;59(5):1057-1059.

[23] Prior RL, Lazarus SA, Cao G, Muccitelli H, Hammerstone JF. Identification of procyanidins and anthocyanins in blueberries and cranberries (Vaccinium spp.) using high-performance liquid chromatography/mass spectrometry. J Agric Food Chem. 2001;49(3):1270-1276.

* Corresponding author.

E-mail: g.srzednicki@unsw.edu.au

Fax: +61 29385 5931; Tel: +61 293854355 

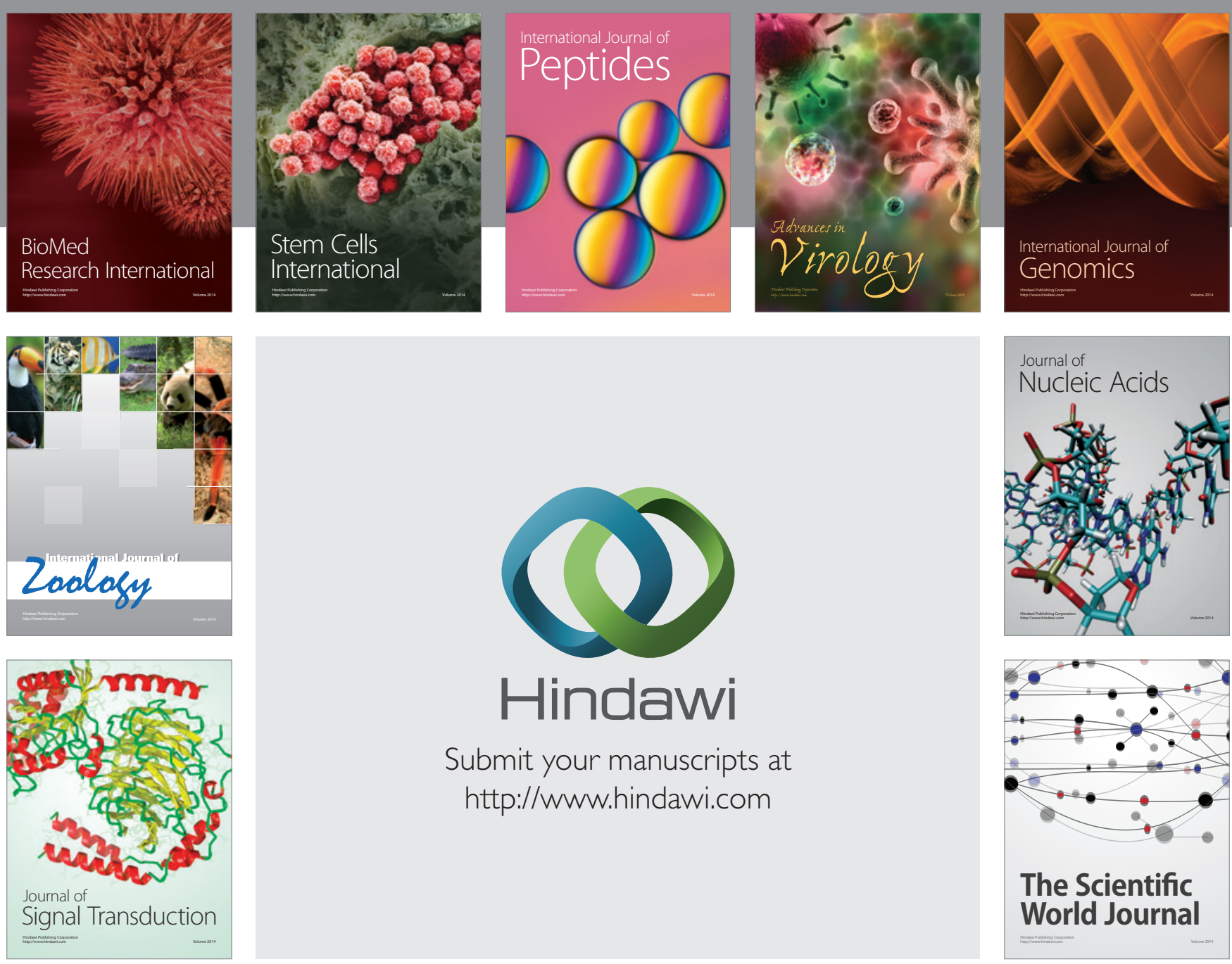

Submit your manuscripts at

http://www.hindawi.com
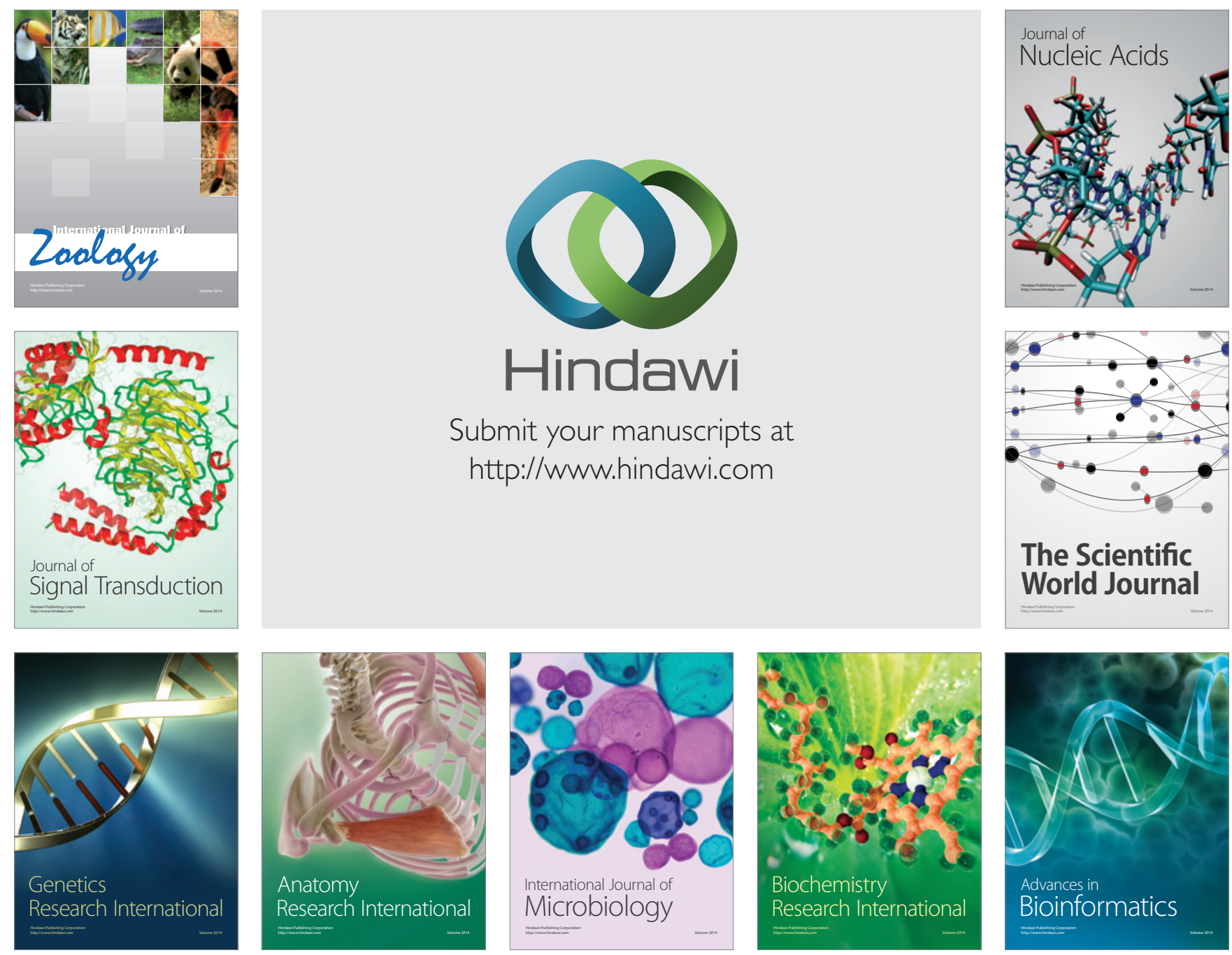

The Scientific World Journal
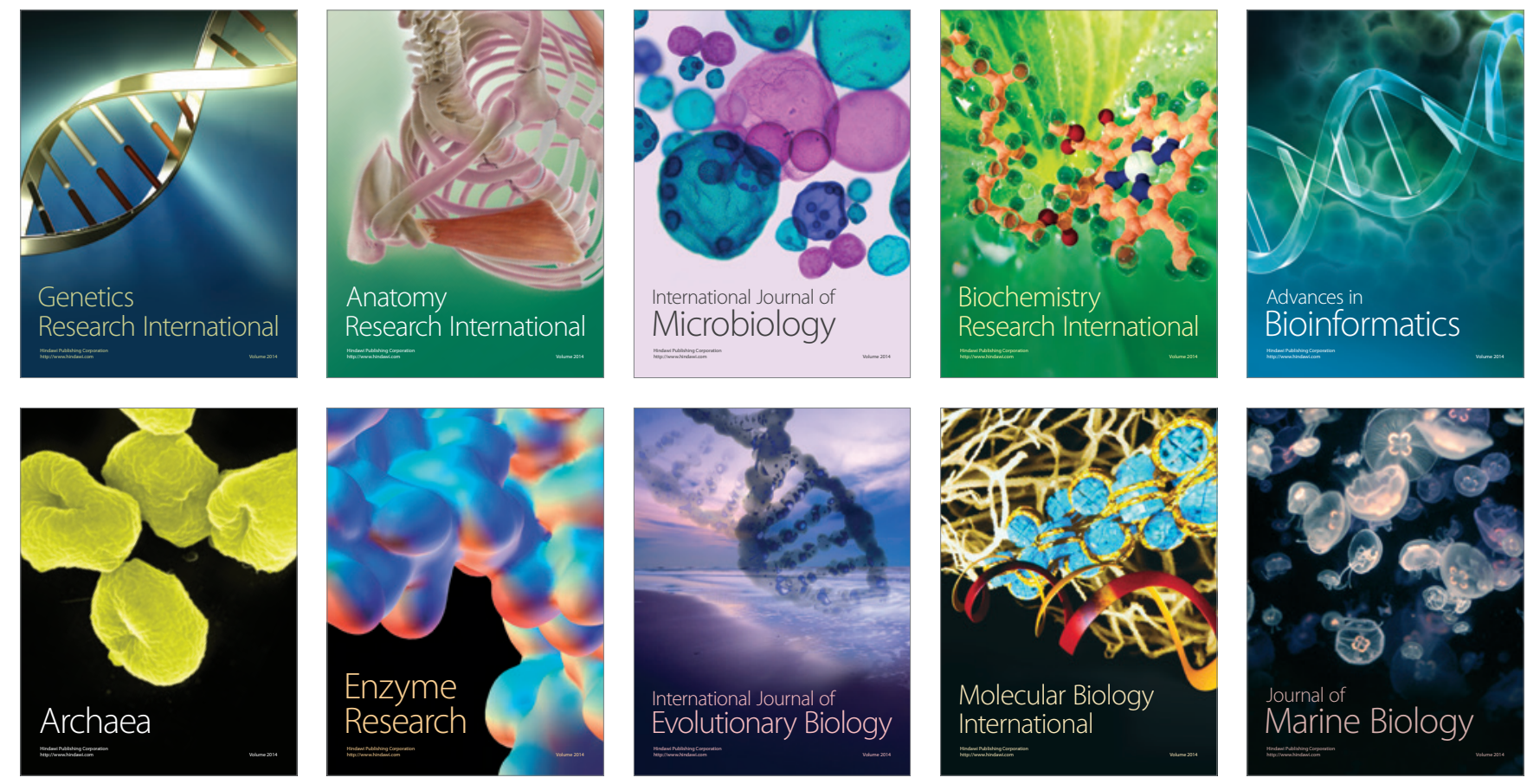